\title{
Cirrhosis related functionality characteristic of the fecal microbiota as revealed by a metaproteomic approach
}

\author{
Xiao Wei ${ }^{1}$, Shan Jiang ${ }^{1}$, Yuye Chen², Xiangna Zhao ${ }^{1}$, Huan Li', Weishi Lin', Boxing Li', Xuesong Wang ${ }^{1}$, \\ Jing Yuan ${ }^{1 *}$ and Yansong Sun ${ }^{1 *}$
}

\begin{abstract}
Background: Intestinal microbiota operated as a whole and was closely related with human health. Previous studies had suggested close relationship between liver cirrhosis (LC) and gut microbiota.

Methods: To determine the functional characteristic of the intestinal microbiota specific for liver cirrhosis, the fecal metaproteome of three LC patients with Child-Turcotte-Pugh (CTP) score of A, B, and C, and their spouse were first compared using high-throughput approach based on denaturing polyacrylamide gel electrophoresis and liquid chromatography-tandem mass spectrometry in our study.

Results: A total of 5,020 proteins ( $88 \%$ from bacteria, $12 \%$ form human) were identified and annotated based on the $\mathrm{GO}$ and KEGG classification. Our results indicated that the LC patients possessed a core metaproteome including 119 proteins, among which 14 proteins were enhanced expressed and 7 proteins were unique for LC patients compared with the normal, which were dominant at the function of carbohydrate metabolism. In addition, LC patients have unique biosynthesis of branched chain amino acid (BCAA), pantothenate, and CoA, enhanced as CTP scores increased. Those three substances were all important in a wide array of key and essential biological roles of life.

Conclusions: We observed a highly comparable cirrhosis-specific metaproteome clustering of fecal microbiota and provided the first supportive evidence for the presence of a LC-related substantial functional core mainly involved in carbohydrate, BCAA, pantothenate, and CoA metabolism, suggesting the compensation of intestinal microbiota for the fragile and innutritious body of cirrhotic patients.
\end{abstract}

Keywords: Cirrhosis, Metaproteome, Fecal microbiota, BCAA,

\section{Background}

Human intestinal tract is colonized by a complex and intimate microbial community that is maintained from early to late adulthood [1]. Human intestinal microbiota was an important organ which has been neglected for a long time. A lot of evidence has suggested that intestinal microbiota works as a whole and plays an important role in human health [2].

Cirrhosis is a condition in which the liver failed to work properly due to long-term damage. The anatomy and

\footnotetext{
*Correspondence: yuanjing6216@163.com; sunys@qq.com ${ }^{1}$ Institute of Disease Control and Prevention, Academy of Military Medical Sciences, No. 20 Dongda Street, Fengtai District, 100071 Beijing, China Full list of author information is available at the end of the article
}

physiological functions of liver and intestinal microbiota share a close relationship as a result of enterohepatic circulation. As the cirrhosis worsen, it was usually accompanied with intestinal inflammation, which may affect the prognosis significantly [3]. Previous studies had revealed the important influence of gut microbiota dysbiosis on the complications of advanced liver cirrhosis (such as spontaneous bacterial peritonitis and hepatic encephalopathy) [4] and on the induction and progress of liver damage at early cirrhosis (such as alcoholic hepatitis and nonalcoholic fatty liver disease) [5]. It has been identified that extensive differences in the microbiota community and metabolic potential existed in the fecal microbiota of cirrhotic patients, and the prevalence of 
potentially pathogenic bacteria, such as Enterobacteriaceae and Streptococcaceae, with the reduction of beneficial populations such as Lachnospiraceae in patients with cirrhosis may affect prognosis [3, 6]. In addition, The functional diversity was significantly reduced in the fecal microbiota of cirrhotic patients compared with in the controls. At the module or pathway levels, the fecal microbiota of the HBLC patients showed enrichment in the metabolism of glutathione, branched-chain amino acid, nitrogen, and lipid, whereas there was a decrease in the level of aromatic amino acid, bile acid and cell cycle related metabolism [3]. These high-throughput analyses lay the groundwork for predicting the protein potential of the intestinal microbiota. However, the functional and metabolic associations between intestinal microbiota and cirrhosis in humans are still lacking.

The rapidly increasing catalogue of proteins from intestinal origin provides a platform for high-throughput functional characterization [7]. In the past 20 years, more and more interests were focused on fecal microbiota, partly due to the fast emerging sequencing technique. Given that proteins are much more actual and stable, proteome-based analyses can be expected to provide a more accurate and real view of the functionality of the intestinal microbiota. The LC-MS/MS method has a higher level of proteome coverage, and is more efficient and accurate to analyze differential global protein expression quantitatively and qualitatively. So far there have been several reports related with the use of metaproteomics to characterize complex bacterial ecosystems $[8,9]$. 2015, Hernández E et al. collected intestinal microbiota proteins from two adult patients receiving 14-days $\beta$-lactam therapy, seven obese and five lean adolescents, followed by metaproteome measurements, to assess the functional differences and metabolic effects in human gastrointestinal tract related with antibiotic treatment and obesity [10]. 2012, Pérez-Cobas AE carried out the multi-omic research on fecal samples from one patient subjected to a $\beta$-lactam intravenous therapy, which suggested that antibiotics may ultimately alter the energy metabolism balance in human gastrointestinal tract [11]. 2012, faecal samples were collected from 3 healthy female subjects over a period of six to twelve months to research the composition and stability of human intestinal metaproteome [12]. 2006, Klaassens ES et al. collected fecal samples from two infants at different ages to characterize the complex intestinal bacterial structure, and illustrated the feasibility of metaproteomic approach in analyzing complex mciroecosystem [13].

In this work, human intestinal microbiota was regarded as a whole to analyze. A high-throughput LC-MS/MS measurement were used to detect the metaproteomic changes in the intestinal microbiota of LC patients. This is the first culture-independent metaproteomic analysis in the gastrointestinal tract from cirrhotic patients.
Our findings may provide a more comprehensive understanding of fecal microbiota in patients with cirrhosis, and generate novel perspectives on the progress and prognosis of cirrhosis.

\section{Methods}

\section{Fecal samples}

The Child-Turcotte-Pugh (CTP) scoring system was used to assess the severity of cirrhosis. Three LC patients (CTP score of $\mathrm{A}, \mathrm{B}, \mathrm{C}$ ) and their corresponding spouse, in the age range of 50-60 and with a body mass index $(\mathrm{BMI})=$ $18.5-24.9 \mathrm{~kg} \mathrm{~m}^{-2}$, were enrolled in this study. Cirrhosis was diagnosed according to the gold standard of biopsy in all patients. Cases that had other complications (such as peritonitis or hepatic encephalopathy) were excluded in this study. All healthy individuals had normal liver biochemistry test results with no evidence of hepatic or other diseases. None of the subjects had food preferences, or received antibiotics, probiotics, steroids or other hormones (including oral, intramuscular or intravenous injection) for at least 3 months before enrolment. Each object was asked to provide a fresh stool sample, which were subjected to metaproteome extraction immediately. This study was approved by the Institutional Review Board of Affiliated Hospital of Academy of Military Medical Sciences. All participants signed an informed consent form prior to entering the study. The study conformed to the ethical guidelines of the 1975 Declaration of Helsinki.

\section{Protein extraction}

Faecal samples were resuspended in PBS and vortexed to homogenize the sample. Proteins were precipitated in pre-chilled TCA (trichloroacetic acid)-acetone (50 g TCA dissolved in $500 \mathrm{ml}$ acetone) at $-20{ }^{\circ} \mathrm{C}$ for $2 \mathrm{~h}$. After centrifugation at $20,000 \times \mathrm{g}$ for $30 \mathrm{~min}$, the protein pellet was washed with pre-chilled acetone and ultrasonicated in lysis buffer (8 M urea, $30 \mathrm{mM}$ HEPES (4-(2-Hydroxyethyl)1-piperazineethanesulfonic acid), $1 \mathrm{mM}$ PMSF (Phenylmethanesulfonyl fluoride), $2 \mathrm{mM}$ EDTA (Ethylene Diamine Tetraacetie Acid), $10 \mathrm{mM}$ DTT (DL-Dithiothreitol)). After centrifugation at $20,000 \times \mathrm{g}$ for $30 \mathrm{~min}$, the supernatant were reduced with $10 \mathrm{mM}$ DTT at $56{ }^{\circ} \mathrm{C}$ for $1 \mathrm{~h}$, and alkylated with $55 \mathrm{mM}$ IAM (iodoacetamide) at room temperature for $1 \mathrm{~h}$ in the dark. The treated proteins were precipitated in pre-chilled acetone at $-20{ }^{\circ} \mathrm{C}$ for $3 \mathrm{~h}$. After centrifugation at $20,000 \times \mathrm{g}$ for $30 \mathrm{~min}$, the protein pellet was resuspended and ultrasonicated in pre-cooled $50 \%$ TEAB (tetraethylammonium bromide) buffer with $0.1 \%$ SDS, and then centrifuged at 20,000 $\times \mathrm{g}$ to pellet the undissolved substance. The protein concentrations were measured by Bradford assay. 


\section{$1 \mathrm{D}$ gel electrophoresis and in-gel protein digestion}

To reduce the complexity of the protein extract, a 1D gel fractionation according to molecular weight was carried out. Equal volumes of protein solutions were mixed with $4 \times$ Laemmli buffer and Biorad reducing agent and run on NuPAGE 4-12\% Bis-Tris gels (Invitrogen) at a constant voltage of $80 \mathrm{~V}$ for 20 min followed by $200 \mathrm{~V}$ for $30 \mathrm{~min}$. Gels were stained with PageBlue (Fermentas). Gel pieces were washed and proteins reduced, alkylated and tryptically digested overnight as described previously [14].

\section{LC-MS/MS measurements}

Peptide samples were analyzed by LC-MS/MS on a quadrupole-Orbitrap mass spectrometer (Q-Exactive; Thermo Fisher, Germany) equipped with a $15 \mathrm{~cm}$ (length) by $75 \mu \mathrm{m}$ (inside diameter) column packed with $5 \mu \mathrm{m}$ C18 medium (150A, Thermo Fisher) which was remained at $21{ }^{\circ} \mathrm{C}$ throughout the analysis. Mobile phase A was MilliQ water with $0.1 \%(v / v)$ formic acid. Mobile phase B was $99.9 \%(v / v)$ acetonitrile and $0.1 \%$ acetic acid. Gradient was run from $0 \% \mathrm{~B}$ to $30 \% \mathrm{~B}$ over $40 \mathrm{~min}$ and then to $80 \%$ B for $15 \mathrm{~min}$. An electrospray voltage of $1.8 \mathrm{kV}$ was applied. By data-dependent acquisition, the mass spectrometer was programmed to acquire tandem mass spectra from the top 20 ions in the full scan from 350 to $2,000 \mathrm{~m} / \mathrm{z}$. Dynamic exclusion was set to $15 \mathrm{~s}$, singly charged ions were excluded, the isolation width was set to $2 \mathrm{~m} / \mathrm{z}$. The full MS resolution was set to 70,000 , and the MS/MS resolution to 17,500 . Normalized collision energy was set to 28 , automatic gain control to $1 \mathrm{e} 6$, maximum fill MS to $20 \mathrm{~ms}$, maximum fill MS/MS to $60 \mathrm{~ms}$, and the under fill ratio to $0.1 \%$. Each sample was repeated triply.

\section{Protein identificaton}

Peptide identification were performed using Mascot v2.3.01 (Matrix Science Ltd.) (http://www.matrixscience.com) licensed in-house (http://www.proteomics.cn) [15]. Monoisotopic peptide masses were used to search the databases, allowing a peptide mass accuracy of $30 \mathrm{ppm}$ and fragment ion tolerance of 0.2 Dalton. Both methionine oxidation and cysteine carboxyamidomethylation were considered in the process. For protein identification, peptide masses were searched against the publically available database for Uniprot-Human database and Uniprot-Bacteria database. For unambiguous identification of proteins, more than five peptides must be matched and the sequence coverage must be greater than $15 \%$.

\section{Bioinformatic analysis}

Microbial proteins which had at least one peptide identification in each individual were defined. Functional classification of identified proteins was performed by BLASTPGP [16] searching against the databases of Cluster of Orthologous Groups database (COGs, ftp://ftp.ncbi.nih.gov/pub/COG/COG2014/static/lists/ listCOGs.html) [17]. The COG associated with the best BLAST hit ( $\leq 1 \mathrm{E}-10$ cutoff) was assigned to the query protein. The identified COGs were mapped on the KEGG metabolic pathways and visualized with the online application of iPath [18]. The spectra those proteins were identified with were taken to sum on COG level per all measurements and were used to rank the COGs according to spectra number. Sequences which did not hit any specific COG were subjected to BLAST search against the NCBI non-redundant database. The cellular localizations of the proteins were predicted by PSORTb version 3.0 [19]. Prediction of signal peptides was carried out with SignalP Version 4.1 [20]. The metaproteomic data from three LC patients (CTP score of A, B, C) were compared with their corresponding spouse, respectively.

\section{Results}

Identification of proteins and metabolic pathways in the fecal metaproteome

Three LC patients with CTP score of A, B, C (coded as $\mathrm{AP}, \mathrm{BP}, \mathrm{CP}$ ) and their corresponding spouse (coded as $\mathrm{AN}, \mathrm{BN}, \mathrm{CN}$ ) were enrolled in this study. Characteristics of the subjects were given in Table 1. Unprocessed fecal material from those subjects were used not only to

Table 1 Characteristics of the patients and controls

\begin{tabular}{|c|c|c|c|c|c|c|}
\hline Terms & $\mathrm{AP}$ & AN & $\mathrm{BP}$ & $\mathrm{BN}$ & $C P$ & $\mathrm{CN}$ \\
\hline Age & 52 & 50 & 59 & 56 & 51 & 50 \\
\hline Gender & Male & Female & Male & Female & Male & Female \\
\hline BMI index & 24.1 & 24.3 & 25.3 & 25.1 & 24.9 & 25.0 \\
\hline Total bilirubin ( $\mu \mathrm{mol} / \mathrm{L})$ & 6.6 & - & 11.8 & - & 36.3 & - \\
\hline Albumin (g/L) & 37.1 & - & 30.5 & - & 26.2 & - \\
\hline Stage of hepatic encephalopathy & 0 & - & 0 & - & 1 & - \\
\hline Ascites degree & No & - & Moderate & - & Severe & - \\
\hline Prothrombin time prolonged (seconds) & 0 & - & 2 & - & 2.1 & - \\
\hline CTP & A & - & B & - & C & - \\
\hline
\end{tabular}


reappear the intestinal microbial proteome characteristics, but also to allow detection of human proteins. Fecal metaproteome were extracted and subjected to 1D-gel (Fig. 1a). A total of over 100,000 spectra were generated by the collection of LC-MS/MS. The raw data has been uploaded to the public websites (http://www.iprox.org/ my/index, user ID: reviewer 719, password: 6s6kd6lp). In this study, a total of 5,020 proteins were identified with two or more peptide identifications, including 4,401 (88 \%) from bacteria proteins and 619 (12\%) from human proteins (Fig. 1b). Results from the annotation to UniprotBacteria database suggested that almost equal and 600 proteins were identified from $\mathrm{AP}$ and $\mathrm{AN}$, and 1100 and 1102 proteins identified from $\mathrm{BP}$ and $\mathrm{CP}$ respectively, almost twice more than their controls. Results of the fecal metaproteome assigned to Uniprot-Human database suggested a relatively stable expression and an average of 100 proteins were identified from each sample (Fig. 1c). Annotation results of bacterial proteins and human proteins from each sample were shown in Additional file 1: Table S1 and Additional file 2: Table S2. To retrieve further functional information, we annotated these proteins based on the GO and KEGG classification and the overall number of proteins identified were shown in Table 2.

\section{Core metaproteome specific for LC patients}

To obtain the LC-related common microbial core proteome, we selected proteins that were found in all the three patients. A total of 119 proteins fulfilled this criterion and their description and functional characteristics were shown in Additional file 3: Table S3. The common and core metaproteome could be grouped into 18 COGs and the most predominant functional categories were $J$ (translation), G (carbohydrate transport and metabolism), C (energy production and conversion), $\mathrm{F}$ (nucleotide transport and metabolism), and $\mathrm{E}$ (amino acid transport and metabolism) (Fig. 2). Nearly $19 \%$ proteins could be assigned to carbohydrate transport and metabolism, and $8 \%$ assigned to amino acid transport and metabolism, reflecting the high metabolic activity of the intestinal microbiota from LC patients. Among those 119 core proteins, 14 proteins enhanced their expression levels and 7 proteins were specific for LC patients compared with the normal, which were described as below.

\section{Differential fecal microbial metabolism and proteins in LC patients}

Fourteen KEGG pathway maps were detected to have different metabolic capacities in the fecal microbiota between
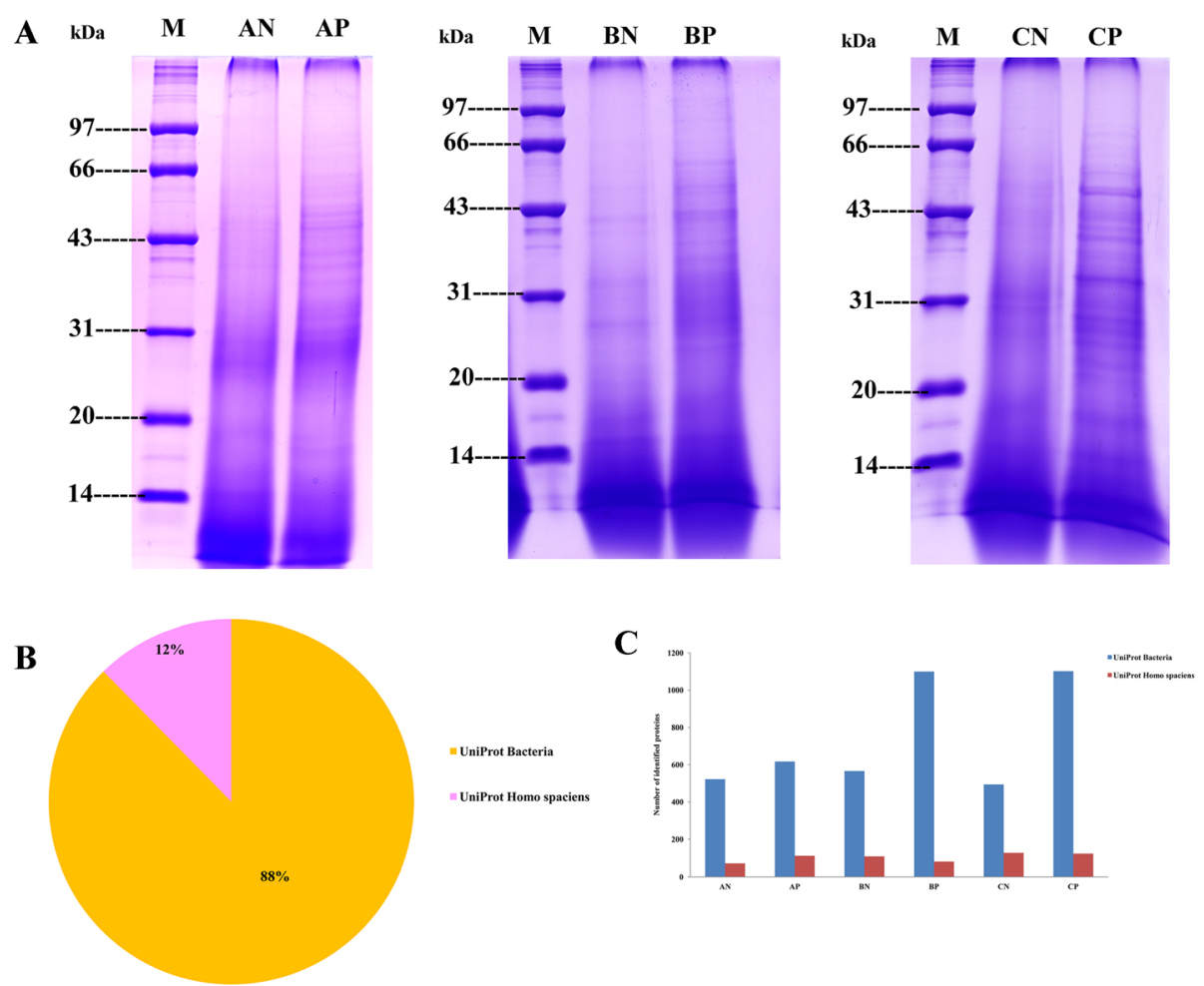

Fig. 1 Electrophoresis maps and annotation results of the fecal metaproteome from six subjects. a The 1D-gel showing the protein pattern from fecal metaproteome of six subjects. b Proportion of proteins allocated to uniprot-bacteria and uniprot-human databases. In this study, a total of 5,020 proteins were identified with two or more peptide identifications, in which $88 \%$ from bacteria proteins and $12 \%$ from human proteins. c Number of proteins allocated to uniprot-bacteria and uniprot-human databases in each sample 
Table 2 Overall number of proteins identified from patients and the normal

\begin{tabular}{|c|c|c|c|c|}
\hline & \multicolumn{2}{|c|}{ Uniprot-Bacteria } & \multicolumn{2}{|c|}{ Uniprot-Human } \\
\hline & Patients & Normal & Patients & Normal \\
\hline Total Protein Number & 2,819 & 1,582 & 314 & 305 \\
\hline \multicolumn{5}{|c|}{ GO (Cellular Component) } \\
\hline Number of $\mathrm{GO}^{\mathrm{a}}$ & 93 & 81 & 171 & 190 \\
\hline Number of Proteins ${ }^{b}$ & 1,213 & 594 & 87 & 98 \\
\hline \multicolumn{5}{|l|}{ GO (Biological Process) } \\
\hline Number of $\mathrm{GO}^{\mathrm{a}}$ & 1,004 & 781 & 867 & 1,082 \\
\hline Number of Proteins ${ }^{b}$ & 1,890 & 954 & 75 & 92 \\
\hline \multicolumn{5}{|c|}{ GO (Molecular Function) } \\
\hline Number of $\mathrm{GO}^{\mathrm{a}}$ & 861 & 596 & 230 & 248 \\
\hline Number of Proteins ${ }^{b}$ & 2,173 & 1,092 & 91 & 110 \\
\hline \multicolumn{5}{|l|}{ KEGG } \\
\hline Number of KEGG ${ }^{a}$ & 127 & 100 & 106 & 123 \\
\hline Number of Proteins ${ }^{\mathrm{b}}$ & 1,697 & 865 & 80 & 80 \\
\hline
\end{tabular}

${ }^{\mathrm{a} N u m b e r}$ of GO terms or KEGG pathways identified

${ }^{\mathrm{b}}$ Number of proteins identified and assigned to corresponding $\mathrm{GO}$ terms or KEGG pathways patients and the normal, including eleven pathways enhanced and three pathways weakened in patients (Additional file 4: Table S4). In the same metabolic pathway, different proteins were identified in different samples, suggesting that the intestinal microbiota have abundant species diversity and protein complexity. In five metabolic pathways, we detected same proteins in different samples, most of which were assigned to carbohydrate metabolism. One of the most predominant pathways was glycolysis/gluconeogenesis, showing high redundancies among microbiota; all the glycolytic/gluconeogenic enzymes could be identified in patients, highlighting the enhanced material metabolism capacity in intestinal microbiota of LC patients.

Fourteen proteins were detected to have enhanced expression level in all the three patients compared with the normal (Table 3), which could be grouped into four COGs (J: Translation, G: Carbohydrate transport and metabolism, E: Amino acid transport and metabolism, O: Posttranslational modification, protein turnover, chaperones), suggesting the enhanced material transport and metabolism function in fecal microbiota from LC patients.

Compatible with the important sugar degradation potential of the gut microbiota, various proteins involved in carbohydrate transport and metabolism were identified and enhanced in patients, including transketolase, transaldolase, xylose isomerase, and glyceraldehyde

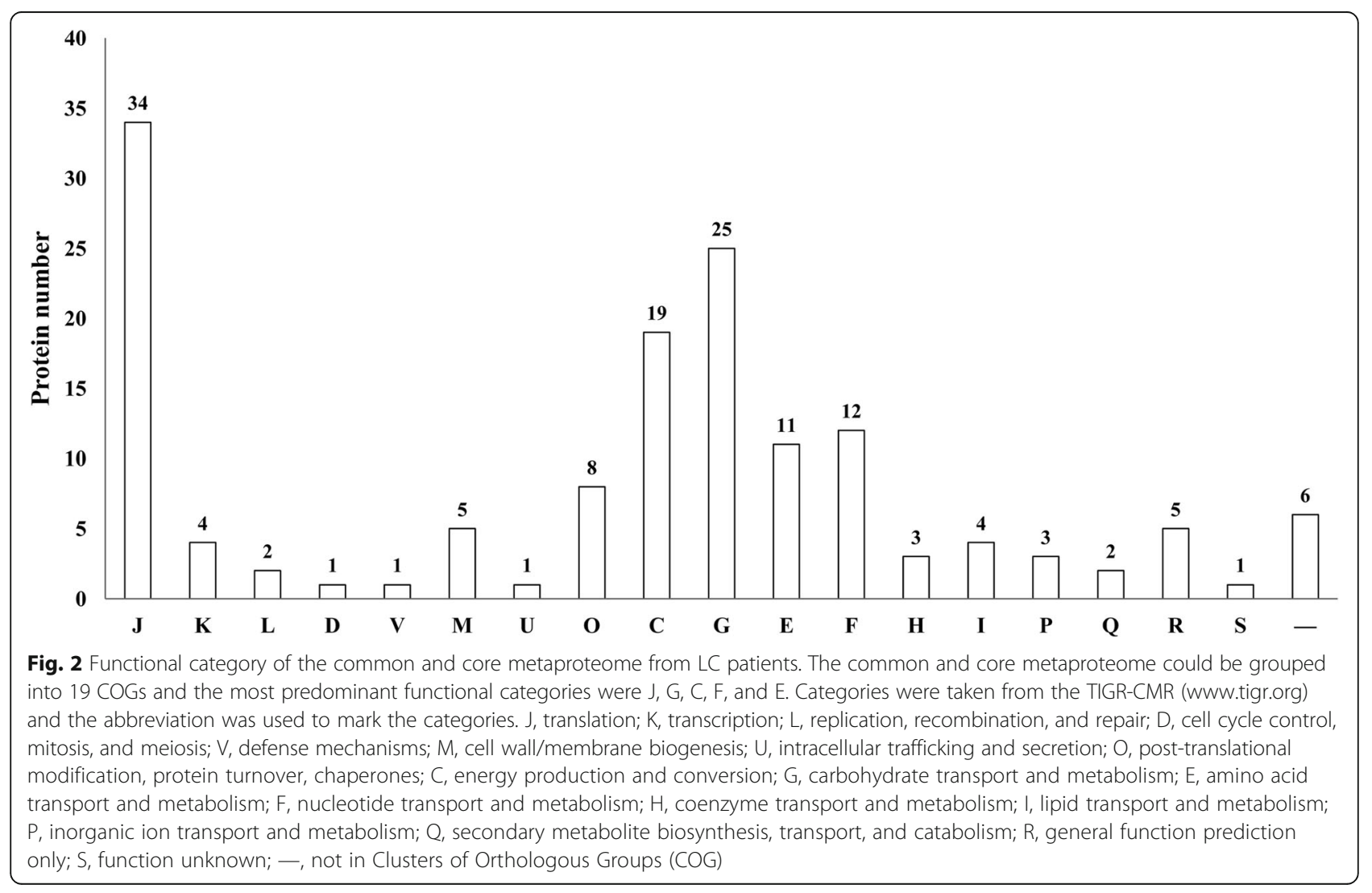


Table 3 Characteristics of proteins with enhanced expression level in the fecal microbiota from LC patients or specific for patients' intestinal microbiota compared with the normal

\begin{tabular}{|c|c|c|c|c|c|c|c|c|c|c|}
\hline No. & Description & Gene name & Length & MW [Da] & $\mathrm{KO}$ & COG & Subcellular location & Signal peptide prediction & $\mathrm{GO}$ & Functonal Category $^{\mathrm{a}}$ \\
\hline \multicolumn{11}{|c|}{ Proteins with enhanced expression level in the fecal microbiota from LC patients } \\
\hline 1 & Chaperone protein DnaK & dnak & 620 & 66,266 & k04043 & COG0443 & Cytoplasmic & Absence & $\begin{array}{c}\text { GO:0006457 } \\
\text { GO:0000166 } \\
\text { GO:0005524 } \\
\text { GO:0051082 }\end{array}$ & O \\
\hline 2 & Glutamate dehydrogenase & pros & 604 & 66,842 & k01881 & COG0442 & Cytoplasmic & Absence & $\begin{array}{c}\text { GO:0006520 } \\
\text { GO:0055114 } \\
\text { GO:0016491 } \\
\text { GO:0016639 }\end{array}$ & J \\
\hline 3 & Elongation factor $\mathrm{G}$ & fusA & 709 & 78,383 & k02355 & COG0480 & Cytoplasmic & Absence & $\begin{array}{c}\text { GO:0006412 } \\
\text { GO:0006414 } \\
\text { GO:0000166 } \\
\text { GO:0003746 } \\
\text { GO:0003924 } \\
\text { GO:0005525 } \\
\text { GO:0005622 } \\
\text { GO:0005737 }\end{array}$ & J \\
\hline 4 & Transketolase & tkt & 702 & 75,877 & k00615 & COG0021 & Cytoplasmic & Absence & $\begin{array}{c}\text { GO:0008152 } \\
\text { GO:0003824 } \\
\text { GO:0004802 } \\
\text { GO:0016740 } \\
\text { GO:0046872 }\end{array}$ & G \\
\hline 5 & 50 S ribosomal protein L25 & rplY & 206 & 21,815 & k02897. & COG1825 & Cytoplasmic & Absence & $\begin{array}{c}\text { GO:0006412 } \\
\text { GO:0003723 } \\
\text { GO:0003735 } \\
\text { GO:0008097 } \\
\text { GO:0019843 } \\
\text { GO:0005840 } \\
\text { GO:0030529 }\end{array}$ & J \\
\hline 6 & Glyceraldehyde 3-phosphate dehydrogenase & BMOU_0196 & 351 & 37,881 & - & - & Cytoplasmic & Absence & $\begin{array}{c}\text { GO:0006006 } \\
\text { GO:0055114 } \\
\text { GO:0016491 } \\
\text { GO:0016620 } \\
\text { GO:0050661 } \\
\text { GO:0051287 }\end{array}$ & - \\
\hline 7 & Glycine-tRNA ligase & glyQS & 446 & 52,295 & k01880 & COG0423 & Cytoplasmic & Absence & $\begin{array}{c}\text { GO:0006412 } \\
\text { GO:0006418 } \\
\text { GO:0006426 } \\
\text { GO:0000166 } \\
\text { GO:0004812 } \\
\text { GO:0004820 } \\
\text { GO:0005524 }\end{array}$ & J \\
\hline
\end{tabular}


Table 3 Characteristics of proteins with enhanced expression level in the fecal microbiota from LC patients or specific for patients' intestinal microbiota compared with the normal (Continued)

\begin{tabular}{|c|c|c|c|c|c|c|c|c|c|c|}
\hline & & & & & & & & & $\begin{array}{l}\text { GO:0016874 } \\
\text { GO:0046983 } \\
\text { GO:0005737 }\end{array}$ & \\
\hline 8 & $60 \mathrm{kDa}$ chaperonin & groL & 541 & 56,837 & k04077 & COG0459 & Cytoplasmic & Absence & $\begin{array}{c}\text { GO:0006457 } \\
\text { GO:0042026 } \\
\text { GO:0000166 } \\
\text { GO:0005524 } \\
\text { GO:0051082 } \\
\text { GO:0005737 }\end{array}$ & O \\
\hline 9 & Elongation factor Tu & tuf & 399 & 43,936 & k02358. & COG0050 & Cytoplasmic & Absence & $\begin{array}{c}\text { GO:0006412 } \\
\text { GO:0006414 } \\
\text { GO:0000166 } \\
\text { GO:0003746 } \\
\text { GO:0003924 } \\
\text { GO:0005525 } \\
\text { GO:0005622 } \\
\text { GO:0005737 }\end{array}$ & J \\
\hline 10 & Xylose isomerase & xylA & 449 & 50,765 & k01805 & COG2115 & Cytoplasmic & Absence & $\begin{array}{c}\text { GO:0005975 } \\
\text { GO:0006098 } \\
\text { GO:0042732 } \\
\text { GO:0000287 } \\
\text { GO:0009045 } \\
\text { GO:0016853 } \\
\text { GO:0046872 } \\
\text { GO:0005737 }\end{array}$ & G \\
\hline 11 & $\mathrm{ABC}$ transporter substrate-binding protein & BBPC_1795 & 430 & 47,488 & K10117 & COG1653 & Cytoplasmic & Absence & $\begin{array}{l}\text { GO:0006810 } \\
\text { GO:0005215 }\end{array}$ & G \\
\hline 12 & Elongation factor Ts & tsf & 283 & 29,835 & k02357 & COG0264 & Cytoplasmic & Absence & $\begin{array}{c}\text { GO:0006412 } \\
\text { GO:0006414 } \\
\text { GO:0003746 } \\
\text { GO:0005622 } \\
\text { GO:0005737 }\end{array}$ & J \\
\hline 13 & Transaldolase & tal & 367 & 39,871 & k00616 & COG0176 & Cytoplasmic & Absence & $\begin{array}{c}\text { GO:0005975 } \\
\text { GO:0006098 } \\
\text { GO:0003824 } \\
\text { GO:0004801 } \\
\text { GO:0016740 } \\
\text { GO:0005737 }\end{array}$ & G \\
\hline 14 & $\mathrm{ABC}$ transporter substrate-binding protein & BBPC_1231 & 550 & 59,251 & K15580 & COG4166 & Cytoplasmic & Absence & $\begin{array}{l}\text { GO:0055085 } \\
\text { GO:0043190 }\end{array}$ & $E$ \\
\hline
\end{tabular}


Table 3 Characteristics of proteins with enhanced expression level in the fecal microbiota from LC patients or specific for patients' intestinal microbiota compared with the normal (Continued)

\begin{tabular}{|c|c|c|c|c|c|c|c|c|c|c|}
\hline \multicolumn{11}{|c|}{ Proteins specific for patients' intestinal microbiota compared with the normal } \\
\hline 1 & Ketol-acid reductoisomerase & ilvC & 350 & 38,768 & - & - & Cytoplasmic & Absence & $\begin{array}{c}\text { GO:0008652 } \\
\text { GO:0009082 } \\
\text { GO:0009097 } \\
\text { GO:0009099 } \\
\text { GO:0055114 } \\
\text { GO:0004455 } \\
\text { GO:0016491 } \\
\text { GO:0016853 }\end{array}$ & - \\
\hline 2 & Phosphoglycerate kinase & pgp & 401 & 41,995 & k00927 & COG0126 & Cytoplasmic & Absence & $\begin{array}{c}\text { GO:0006096 } \\
\text { GO:0016310 } \\
\text { GO:0000166 } \\
\text { GO:0004618 } \\
\text { GO:0005524 } \\
\text { GO:0016301 } \\
\text { GO:0016740 } \\
\text { GO:0005737 }\end{array}$ & G \\
\hline 3 & $50 S$ ribosomal protein $L 4$ & rplD & 221 & 23,761 & K02926 & COG0088 & Unknown & Absence & $\begin{array}{c}\text { GO:0006412 } \\
\text { GO:0003723 } \\
\text { GO:0003735 } \\
\text { GO:0019843 } \\
\text { GO:0005840 } \\
\text { GO:0030529 }\end{array}$ & J \\
\hline 4 & Ribose-phosphate pyrophosphokinase & prs & 337 & 36,843 & K00948 & COG0462 & Cytoplasmic & Absence & $\begin{array}{c}\text { GO:0006015 } \\
\text { GO:0009165 } \\
\text { GO:0016310 } \\
\text { GO:0000166 } \\
\text { GO:0000287 } \\
\text { GO:0004749 } \\
\text { GO:0005524 } \\
\text { GO:0016301 } \\
\text { GO:0016740 } \\
\text { GO:0046872 } \\
\text { GO:0005737 }\end{array}$ & FE \\
\hline 5 & Probable thiol peroxidase & $\operatorname{tpx}$ & 171 & 18,391 & K11065 & COG2077 & Periplasmic & Absence & $\begin{array}{c}\text { GO:0005623 } \\
\text { GO:0045454 } \\
\text { GO:0055114 } \\
\text { GO:0098869 } \\
\text { GO:0004601 } \\
\text { GO:0008379 } \\
\text { GO:0016209 } \\
\text { GO:0016491 } \\
\text { GO:0016684 } \\
\text { GO:0005623 }\end{array}$ & O \\
\hline
\end{tabular}


Table 3 Characteristics of proteins with enhanced expression level in the fecal microbiota from LC patients or specific for patients' intestinal microbiota compared with the normal (Continued)

\begin{tabular}{|c|c|c|c|c|c|c|c|c|c|c|}
\hline 6 & $30 S$ ribosomal protein $\$ 4$ & rpsD & 208 & 23,719 & K02986 & COG0522 & Cytoplasmic & Absence & $\begin{array}{l}\text { GO:0006412 } \\
\text { GO:0003723 } \\
\text { GO:0003735 } \\
\text { GO:0019843 } \\
\text { GO:0005622 } \\
\text { GO:0005840 } \\
\text { GO:0015935 } \\
\text { GO:0030529 }\end{array}$ & J \\
\hline 7 & $50 S$ ribosomal protein L3 & rplC & 213 & 22,687 & K02906 & COG0087 & Cytoplasmic & Absence & $\begin{array}{c}\text { GO:0006412 } \\
\text { GO:0003723 } \\
\text { GO:0003735 } \\
\text { GO:0019843 } \\
\text { GO:0005622 } \\
\text { GO:0005840 } \\
\text { GO:0030529 }\end{array}$ & J \\
\hline
\end{tabular}

a Categories were taken from the TIGR-CMR (www.tigr.org) and the abbreviation was used to mark the categories. J Translation, $O$ Posttranslational modification, protein turnover, chaperones, $G$ Carbohydrate transport and metabolism, E Amino acid transport and metabolism, $F$ Nucleotide transport and metabolism; - : not in COGs 
3-phosphate dehydrogenase, which were grouped into the KEGG pathway of map 00030 (Pentose phosphate pathway), map 00040 (Pentose and glucuronate interconversions), map 00051 (Fructose and mannose metabolism), map 00010 (Glycolysis/Gluconeogenesis), as well as map 01110 (Biosynthesis of secondary metabolites). The abundance of bacterial proteins devoted to the utilization of carbohydrates testified for their importance as metabolic substrates in the intestinal tract.

The most significantly differential protein was glyceraldehyde 3-phosphate dehydrogenase (EC1.2.1.12), which catalyzes the oxidative phosphorylation of glyceraldehyde 3-phosphate (G3P) to 1,3-bisphosphoglycerate (BPG) using the cofactor NAD. This protein is involved in step 1 of the subpathway, part of carbohydrate degradation and glycolysis pathway, that synthesizes pyruvate from Dglyceraldehyde 3-phosphate. 3-phosphoglycerate kinase assists in the transformation of 3-phospho-D-glycerate to 3phospho-D-glyceroyl phosphate by consumption of ATP.

Another significantly differential protein was glutamate dehydrogenase (GDH). Moreover, detailed analysis of these peptides revealed GDH to show a high level of redundancy in the intestinal tract since we could identify it as a major protein in a large variety of bacterial families, including Bacteroidaceae, Streptococcaceae, Ruminococcaceae and Bifidobacteriaceae (Additional file 1: Table S1). It is known that GDH not only links the nitrogen and the carbon-cycle via the incorporation of ammonia into 2-ketoglutarate, but also have another metabolic role and act as an electron sink [12]. This pathway, which operates in several strict anaerobes to assure a low level of free electrons, resulting in the net conversion of pyruvate and ammonia into alanine while consuming $\mathrm{NAD}(\mathrm{P}) \mathrm{H}$ that can be generated via a ferredoxin NAPDH oxidoreductase [12]. This potential role of intestinal GDH as an electron sink requires the activity of aminotransferases, many of which were identified in the metaproteome, including branched-chain amino acid aminotransferase, aminotransferase class- $V$ family protein, phosphoserine aminotransferase, taurine-pyruvate aminotransferase, aspartate/tyrosine/aromatic aminotransferase, glucosaminefructose-6-phosphate aminotransferase, acetylornithine aminotransferase, $\mathrm{N}$-succinyldiaminopimelate aminotransferase, histidinol-phosphate aminotransferase, 4-aminobutyrate aminotransferase, which were all specially enhanced in $\mathrm{BP}$ and $\mathrm{CP}$ patients.

\section{Unique fecal microbial proteins and metabolism for LC patients}

To identify the fecal microbiota proteins specific for patients, we selected proteins that were found only in all the three patients but absent in the normal. A total of seven proteins fulfill the criterion. Charicteristics of unique fecal microbial proteins for LC patients were shown in Table 3.

Additionally, Two KEGG pathways, map 00290 (Valine, leucine and isoleucine biosynthesis) and map 00770 (Pantothenate and CoA biosynthesis) were common in the fecal microbiota from the three patients and absent in normal. As the patients' condition worse, the number of specific enzymes from the two metabolic pathways were remarkably increased, and the metabolic pathways were enhanced. In patient $\mathrm{CP}$, the specific enzymes from map 00290 and map 00770 were almost covered the whole metabolic pathway (Fig. 3). LC patients have an enhanced function of branched-chain amino acid (BCAA) and vitamin metabolism, which were in accordance with the metagenomic results from Wei [21].

The most unique enzymes detected were ketol-acid reductoisomerase (EC 1.1.1.86) and dihydroxy-acid dehydratase (EC 4.2.1.9). Degradation of BCAA involved the branched-chain alpha-keto acid dehydrogenase complex. Those two enzymes were both important in the KEGG pathways of map 00290 and map 00770 and have the protein interactions of neighborhood and coexpression.

Ketol-acid reductoisomerase (EC 1.1.1.86), specific in fecal microbiota from patients, were key enzyme from metabolic pathway of valine, leucine and isoleucine biosynthesis and pantothenate and CoA biosynthesis. This enzyme can catalyse the reduction of 2-ethyl-2-hydroxy3-oxobutanoate to 2,3-dihydroxy-3-methylpentanoate. This protein is involved in step 2 of the subpathway that synthesizes $\mathrm{L}$-valine from pyruvate and L-isoleucine from 2-oxobutanoate, which are part of the pathway of $\mathrm{L}$-valine biosynthesis and L-isoleucine biosynthesis, respectively. The chemical reactions and pathways resulting in the formation of valine, 2-amino-3-methylbutanoic acid and isoleucine, $\left(2 \mathrm{R}^{*}, 3 \mathrm{R}^{*}\right)$-2-amino-3-methylpentanoic acid. In addition, this enzyme is involved in step 2 of the subpathway that synthesizes patothenate from pyruvate, which are part of the pathway of Pantothenate and CoA biosynthesis.

Dihydroxy-acid dehydratase (EC 4.2.1.9), specific in the fecal microbiota from BP and CP, catalyzes third step in the common pathway leading to biosynthesis of branchedchain amino acids and is important in the KEGG pathway of map 00290 and map 00770. This protein is involved in step 3 of the subpathway that synthesizes L-isoleucine from 2-oxobutanoate and L-valine from pyruvate, which are part of the pathway of L-valine biosynthesis and L-isoleucine biosynthesis, respectively.

Branched-chain-amino-acid transaminase (EC 2.6.1.42), specific in the fecal microbiota from $\mathrm{BP}$ and $\mathrm{CP}$, belongs to the class-IV pyridoxal-phosphate-dependent aminotransferase family. Branched-chain-amino-acid transaminase can catalyze the transfer of an alpha-amino group from an amino acid to an alpha-keto acid leading to 


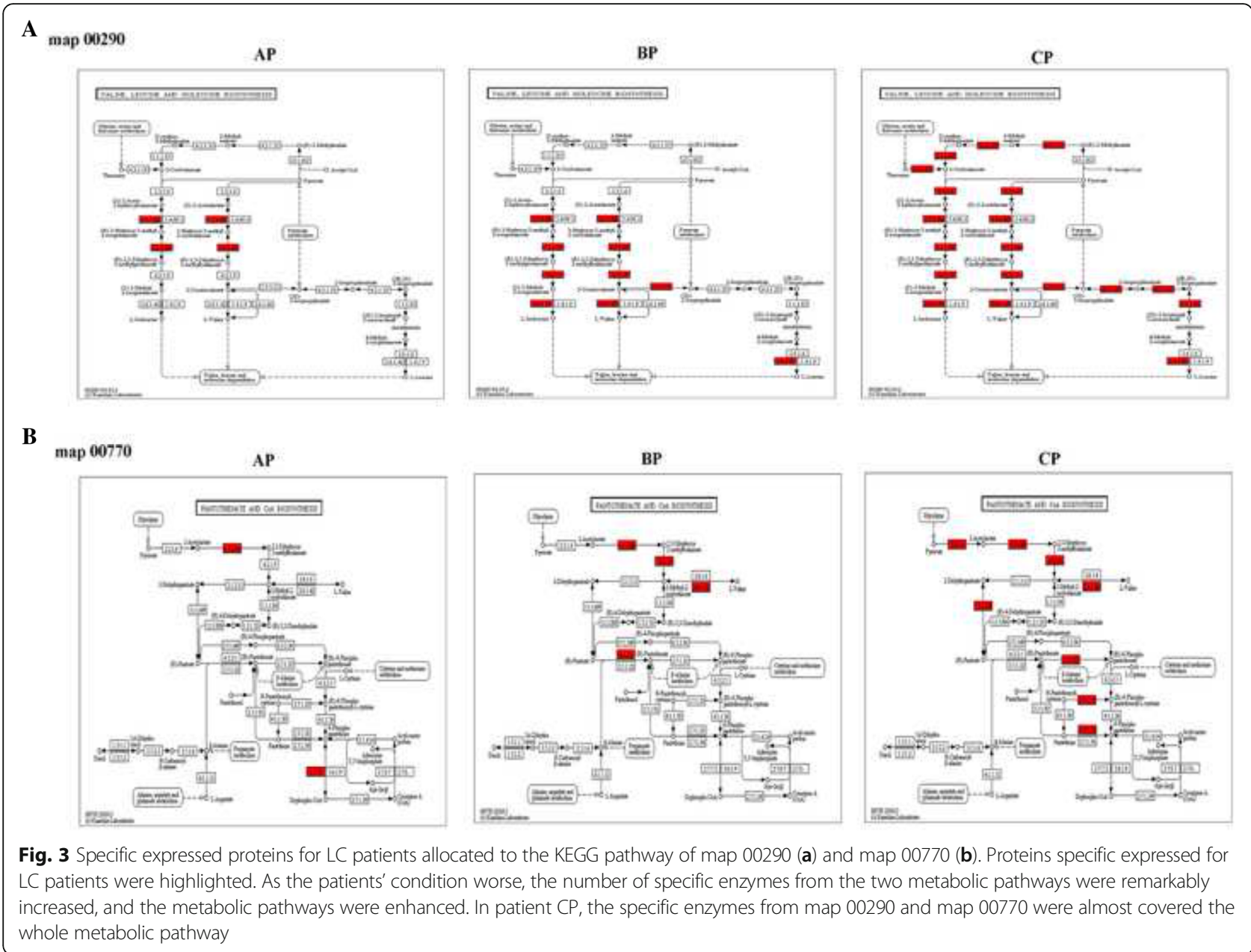

biosynthesis of branched-chain amino acids and is important in the KEGG pathway of map 00290 and map 00770. The amino group is usually covalently bound by the prosthetic group pyridoxal phosphate.

\section{Non-bacterial proteins}

The vast majority of the identified proteins, approximately $87.7 \%$, were of microbial origin. Moreover, in total, 619 human proteins, excluding possible contaminants [22], were identified as representing host cell activity along the digestive tract. In general, the identified human proteins were mostly involved in carbohydrates and proteins digestion, maintaining mucosal barrier function, and providing energy resources for intestinal microbes.

\section{Discussion}

In any microbiome environment, expression of microbiota proteins were all closely affected by the microenvironment and bacteria-host interactions [23]. However, culture-based research was unable to reappear the real condition of microbiome in the environment and the insufficient microbiome sequence information confounded identification of the proteins [12]. Currently, people were focusing more and more interests on metaproteomics approaches to monitor the disease related functional products of the microbiota [13], and the ongoing protein library analysis enabled meaningful identification in time [2, 24]. For the first time, extraction of metaproteome from LC patients and tentative identification using LC-MS/MS were carried out in this study. To retrieve further functional information, we annotated these proteins based on the GO and KEGG classification and analyzed the characteristic of the intestinal microbiota from LC patients at the expression level.

As revealed by the protein identification searched against the publically available database for Uniprot-Bacteria database, nearly equal proteins were identified from AP and $\mathrm{AN}$, however, almost twice proteins were identified from BP and CP compared with the normal, implying that as the disease processed, the changes in intestinal microenvironment caused by cirrhosis compelled fecal microbiota to enhance their growth activity and protein expression to survival.

A LC-related core metapoteome including 119 proteins was described in this study. Majority of the proteins could 
be assigned to carbohydrate and amino acid transport and metabolism, reflecting the active metabolic ability of the intestinal microbiota from LC patients. Among those 119 core proteins, 14 proteins, involved in carbohydrate transport and metabolism, enhanced their expression levels in the fecal microbiota from LC patients, which further illustrated that human gut bacteria encountered a broad spectrum of carbohydrate substrates.

Fourteen KEGG pathway maps were detected to have different metabolic capacities in the fecal microbiota between patients and the normal, including eleven pathways enhanced and three pathways weakened in patients. In the same metabolic pathway, different proteins were identified in different samples, suggesting the abundant species diversity and protein complexcity, that is why we got rid of species boundaries and regarded fecal microbiota as a whole in this study.

Seven proteins were identified as the unique fecal microbial proteins for LC patients compared with the normal. Correspondingly, two KEGG pathways, map 00290 (Valine, leucine and isoleucine biosynthesis) and map 00770 (Pantothenate and CoA biosynthesis), were unique in the fecal microbiota from LC patients. More interestingly, as the patients' condition worse, the patients-specific enzymes were almost covered the whole metabolic pathway. Valine, leucine and isoleucine were all BCAA, which were among the nine essential amino acids for humans. Pantothenate was an essential nutrient for human and used to synthesize CoA, as well as to synthesize and metabolize proteins, carbohydrates, and fats. Pantothenate, in the form of CoA, is also required for acylation and acetylation, which, for example, are involved in signal transduction and enzyme activation and deactivation, respectively $[25,26]$. CoA was important in energy metabolism for pyruvate to enter the TCA cycle as acetyl-CoA, and for $\alpha$-ketoglutarate to be transformed to succinyl-CoA in the cycle, as well as in the biosynthesis of many important compounds such as fatty acids, cholesterol, and acetylcholine [26]. BCAA and pantothenate were both important in a wide array of key biological roles. LC patients were weak fitness and as a result the peripheral tissues need to increase their consumption of a variety of nutrients including carbohydrates, BCAA and vitamins. The specific expression of bacterial proteins devoted to map 00290 and map 00770 testified the compensation for the fragile health and need for nutrition.

\section{Conclusions}

Altogether, we observed a first and highly comparable cirrhosis-specific metaproteome clustering of fecal microbiota. Our findings provided a supportive evidence for the presence of a LC-related substantial metaproteome core which enhanced the expression level involved in sugar transport and degradation, as well as BCAA, pantothenate and CoA biosynthesis. Our results suggested that the fecal microbiota not only had strong adaptability to the intestinal microenvironment, but also could compensate for the fragile and innutritious body of cirrhotic patients.

\section{Additional files}

Additional file 1: Table S1. Protein identification with peptide masses searched against the publically available database for Uniprot-Bacteria database (XLSX $635 \mathrm{~kb}$ )

Additional file 2: Table S2. Protein identification with peptide masses searched against the publically available database for Uniprot-Human database (XLSX $50 \mathrm{~kb}$ )

Additional file 3: Table S3. Core metaproteome of intestinal microbiota from LC patients (DOCX $27 \mathrm{~kb}$ )

Additional file 4: Table S4. Fourteen KEGG pathway maps detected to have different metabolic capacities in the fecal microbiota between patients and the normal (DOC $94 \mathrm{~kb})$

\section{Abbreviations}

BCAA: Branched-chain amino acid; BMI: Body mass index; CTP: Child-

Turcotte-Pugh; DTT: DL-Dithiothreitol; EDTA: Ethylene Diamine Tetraacetie Acid; G3P: Glyceraldehyde 3-phosphate; GDH: Glutamate dehydrogenase; HEPES: 4-(2-Hydroxyethyl)-1-piperazineethanesulfonic acid;

IAM: lodoacetamide; LC: Liver cirrhosis; PMSF: Phenylmethanesulfonyl fluoride; TCA: Trichloroacetic acid; TEAB: Tetraethylammonium bromide

\section{Acknowledgements}

Not applicable.

\section{Funding}

This work was supported by a grant from the National Natural Science Foundation of China (81400592) to X.W. and (31370093) to J.Y., Mega-projects of Science and Technology Research of China (Grant 2011ZX10004-001), the German Academic Exchange Service/Federal Ministry of Education and Research to C.U.R (Grant D/09/04778), and a grant from the National High Technology Research and Development Program of China (863 Program; grant no. SS2014AA022210).

\section{Availability of data and materials}

All data generated or analysed during this study are included in this published article and its supplementary information files.

\section{Authors' contributions}

$Y S, J Y$, and XW designed research; XW, SJ, HL, and WL performed research; $X W, S W, B L$, and $X Z$ contributed new reagents or analytic tools; XW, SJ, and YC analyzed data; XW, YC, and YS wrote the paper. All authors read and approved the final manuscript.

\section{Competing interests}

The authors declare that they have no competing interests.

Consent for publication

All authors approve to publish this paper on BMC gastroenterology.

Ethics approval and consent to participate

This study was approved by the Institutional Review Board of Affiliated Hospital of Academy of Military Medical Sciences. All participants signed an informed consent form prior to entering the study. The study conformed to the ethical guidelines of the 1975 Declaration of Helsinki.

\section{Author details}

${ }^{1}$ Institute of Disease Control and Prevention, Academy of Military Medical Sciences, No. 20 Dongda Street, Fengtai District, 100071 Beijing, China.

${ }^{2}$ Hospital of Traditional Chinese Medicine, Liquan 713200, Shanxi, China. 
Received: 30 December 2015 Accepted: 20 September 2016 Published online: 04 October 2016

\section{References}

1. Turnbaugh PJ, Ley RE, Hamady M, Fraser-Liggett CM, Knight R, Gordon J. The human microbiome project. Nature. 2007;449:804-10.

2. Gill SR, Pop M, Deboy RT, Eckburg PB, Turnbaugh PJ, Samuel BS, et al. Metagenomic analysis of the human distal gut microbiome. Science. 2006;312:1355-9.

3. Usami M, Miyoshi M, Yamashita H. Gut microbiota and host metabolism in liver cirrhosis. World J Gastroenterol. 2015;21:11597-608.

4. Garcia-Tsao G, Wiest R. Gut microflora in the pathogenesis of the complications of cirrhosis. Best Pract Res Clin Gastroenterol. 2004;18:353-72.

5. Benten D, Wiest R. Gut microbiome and intestinal barrier failure-the "Achilles heel" in hepatology? J Hepatol. 2012;56:1221-3.

6. Chen Y, Yang F, Lu H, Wang B, Chen Y, Lei D, et al. Characterization of fecal microbial communities in patients with liver cirrhosis. Hepatol Baltim Md. 2011:54:562-72

7. Zoetendal EG, Rajilic-Stojanovic M, de Vos WM. High-throughput diversity and functionality analysis of the gastrointestinal tract microbiota. Gut. 2008;57:1605-15.

8. Ram RJ, Verberkmoes NC, Thelen MP, Tyson GW, Baker BJ, Blake RC, et al. Community proteomics of a natural microbial biofilm. Science. 2005;308:1915-20.

9. Wilmes P, Bond PL. The application of two-dimensional polyacrylamide gel electrophoresis and downstream analyses to a mixed community of prokaryotic microorganisms. Environ Microbiol. 2004;6:911-20.

10. Hernández E, Bargiela R, Diez MS, Friedrichs A, Pérez-Cobas AE, Gosalbes MJ, et al. Functional consequences of microbial shifts in the human gastrointestinal tract linked to antibiotic treatment and obesity. Gut Microbes. 2013;4:306-15.

11. Ferrer M, Martins dos Santos VAP, Ott SJ, Moya A. Gut microbiota disturbance during antibiotic therapy: a multi-omic approach. Gut Microbes. 2014;5:64-70.

12. Kolmeder CA, de Been M, Nikkilä J, Ritamo I, Mättö J, Valmu L, et al. Comparative metaproteomics and diversity analysis of human intestinal microbiota testifies for its temporal stability and expression of core functions. PLoS One. 2012:7:e29913.

13. Klaassens ES, de Vos WM, Vaughan EE. Metaproteomics approach to study the functionality of the microbiota in the human infant gastrointestinal tract. Appl Environ Microbiol. 2007;73:1388-92

14. Shevchenko A, Tomas H, Havlis J, Olsen JV, Mann M. In-gel digestion for mass spectrometric characterization of proteins and proteomes. Nat Protoc. 2006;1:2856-60.

15. Albrethsen J, Knol JC, Piersma SR, Pham TV, de Wit M, Mongera S, et al. Subnuclear proteomics in colorectal cancer: identification of proteins enriched in the nuclear matrix fraction and regulation in adenoma to carcinoma progression. Mol Cell Proteomics MCP. 2010;9:988-1005.

16. Altschul SF, Madden TL, Schäffer AA, Zhang J, Zhang Z, Miller W, et al. Gapped BLAST and PSI-BLAST: a new generation of protein database search programs. Nucleic Acids Res. 1997;25:3389-402.

17. Tatusov RL, Galperin MY, Natale DA, Koonin EV. The COG database: a tool for genome-scale analysis of protein functions and evolution. Nucleic Acids Res. 2000;28:33-6.

18. Letunic I, Yamada T, Kanehisa M, Bork P. iPath: interactive exploration of biochemical pathways and networks. Trends Biochem Sci. 2008;33:101-3.

19. Yu NY, Wagner JR, Laird MR, Melli G, Rey S, Lo R, et al. PSORTb 3.0: improved protein subcellular localization prediction with refined localization subcategories and predictive capabilities for all prokaryotes. Bioinforma Oxf Engl. 2010;26:1608-15.

20. Petersen TN, Brunak S, von Heijne G, Nielsen H. SignalP 4.0: discriminating signal peptides from transmembrane regions. Nat. Methods. 2011;8:785-6.

21. Wei X, Yan X, Zou D, Yang Z, Wang X, Liu W, et al. Abnormal fecal microbiota community and functions in patients with hepatitis $B$ liver cirrhosis as revealed by a metagenomic approach. BMC Gastroenterol. 2013;13:175.

22. Bragulla HH, Homberger DG. Structure and functions of keratin proteins in simple, stratified, keratinized and cornified epithelia. J Anat. 2009;214:516-59.

23. Qin J, Li R, Raes J, Arumugam M, Burgdorf KS, Manichanh C, et al. A human gut microbial gene catalogue established by metagenomic sequencing. Nature. 2010;464:59-65.

24. Manichanh C, Rigottier-Gois L, Bonnaud E, Gloux K, Pelletier E, Frangeul L, et al. Reduced diversity of faecal microbiota in Crohn's disease revealed by a metagenomic approach. Gut. 2006;55:205-11.
25. Spry C, van Schalkwyk DA, Strauss E, Saliba KJ. Pantothenate utilization by Plasmodium as a target for antimalarial chemotherapy. Infect Disord Drug Targets. 2010;10:200-16.

26. Bernal V, Masdemont B, Arense P, Cánovas M, Iborra JL. Redirecting metabolic fluxes through cofactor engineering: Role of CoA-esters pool during L(-)-carnitine production by Escherichia coli. J Biotechnol. 2007:132:110-7.

\section{Submit your next manuscript to BioMed Central and we will help you at every step:}

- We accept pre-submission inquiries

- Our selector tool helps you to find the most relevant journal

- We provide round the clock customer support

- Convenient online submission

- Thorough peer review

- Inclusion in PubMed and all major indexing services

- Maximum visibility for your research

Submit your manuscript at www.biomedcentral.com/submit
C) Biomed Central 